\title{
Integrating the Webinar as a Tool to Support Adult Training: A Case Study on the Training for Entrepreneurs of SMEs in Thailand
}

\author{
https://doi.org/10.3991/ijet.v16i16.21805 \\ Pakinee Ariya, Kannikar Intawong, Kitti Puritat $\left({ }^{(}\right)$ \\ Chiang Mai University, Chiang Mai, Thailand \\ kitti.pecmu.ac.th
}

\begin{abstract}
The COVID-19 pandemic has presented significant challenges for the education and training sector. We could have witnessed the rise of technology for webinars which are tools to deliver training and education through video and audio communication in the form of distance learning for instructors and participants. However, commercial webinars such as zoom or webex may lack a management system for organizing the amount of participants for long term courses. The present study aimed to develop a webinar tool for the context of adult training for entrepreneurs of SMEs in Thailand. In order to develop a webinar tool, we proposed a general framework which consisted of three stages. The requirement stage aimed to explore the baseline survey from 411 participants and summarize the feature list of the webinar. The development stage employed the kanban methodology to develop each feature list and proposed the architecture of the system. Finally, the evaluation stage compares two groups of 110 participants between our webinar approach and zoom application with statistics of attendance regarding those who attended the course and also contains a satisfaction survey. The results show that the important feature to engage participants in long term courses were system notifications and the availability of a web-based platform for providing easy access to webinar.
\end{abstract}

Keywords—webinar, adult training, Kanban development process, SMEs, learning cycle

\section{Introduction}

In response to industry 4.0, traditional manufacturing is rapidly changing in the direction of using modern smart information systems driven by innovation technology. Accordingly, it provides new jobs and many opportunities for companies to learn the new sets of knowledge and skills [1] especially digital competency skills in three major domains: Latest digital technologies, Digital tools for SMEs and Digitalization of business processes. The market trend and digital processes require competency skills of employees with up-to-date digital technologies to be competitive and successful in their job roles. Thus, organizations need to upgrade the skills of all employees to stay abreast of the latest technology development trends. For Thailand, SMEs (Small and Medium 
Enterprises) consisting of employees are the backbone of the market economy which help the country create fundamental improvements on the domains of economy and society.

For that reason, the Thai government established the Office of SMEs Promotion (OSMEP) which is responsible for promoting and supporting the SMEs in Thailand. One of the duties of OSMEP is to provide the academic training and assistance to all entrepreneurs and employees to enhance their competencies and digital skills in order to drive the overall competition at a national level. For the northern part of Thailand, OSMEP cooperated with Chiang Mai University to provide a program of training for entrepreneurs to upgrade the skills of employees which could successfully developed and implemented in small and medium-sized companies despite both the internal and external barriers SMEs might face.

However, since January 2019, when the first confirmed case of COVID-19 in Thailand was found, the infection situation has been getting worse. Finally, the Thai Government decided to declare a state of emergency and a lockdown on March 26 in order to control the situation of COVID-19. The lockdown situation suddenly shifted the people from every sector forcing them to continue their work remotely with telecommunication technologies and new tools such as webinar or web conference to support education and training programs. Within the context of this study, OSMEP provided funding for Chiang Mai University aiming to develop a tool of technology to support the training of entrepreneurs of SMEs in the northern part of Thailand. One of the objectives was to identify the best practices for the integration of the webinar as a technological tool to improve the digital competency skills as we mentioned before.

On the other hand, the COVID-19 health crisis has stimulated innovation of digital technology within the education and training sectors. Zoom application and Microsoft teams were collaboration platforms that support video communication [2]. However, based on the number of participants of the training program, at least 1000 participants for each year has been separated to many programs. Preliminary tests using the zoom application led to many problems for the management of the participants. The objective of this research is to propose a framework for developing a webinar platform to support adult training programs for entrepreneurs.

- The requirement features of webinars suitable for adult training of SMEs

- The webinar management system for organizing participants of training programs for entrepreneurs of SMEs.

- The software engineering framework for developing webinar to support adult training

This paper is organized as follows: Section 2 describes the related work of webinar for adult learning. Section 3 describes the methodology for the development of webinar. Section 4 describes the requirement stage of the development. Section 5 and section 6 describe the development and evaluation stages for webinar. Finally, Section 7 discusses the conclusions and outlines the Future work. 


\section{Related work}

On the domain of adult training digitalization has rapidly and globally changed the characteristics of training and adult education. It is important for instructors to keep attendants engaged [3] [4] [5] [6]. Commonly, webinar technology were used for infrastructure of training and were applied in blended learning training and distance learning [7] [8] [9].

Recently researchers reported that in distance learning the interaction between instructor and participants were more important in virtual format than in face-to-face systems [10][11] because for successful learning and teaching, the participants feel shy to ask questions when they have a barrier of a digital tool. In addition, reports showed that distance learning can decrease absence from work [12]. However, in terms of specific training, laboratory equipment was not suitable for learning in distance learning.

Commercial Webinar is seeing an exponential growth as millions of people are working from home due to the rapid spread of the coronavirus. According to a report, Zoom, webex and Microsoft teams have been used in recent years to contribute to adult training, meetings and higher education [13][14][15]. Due to the lockdown situation, the zoom platform has been used by many meetings and trainings around the world. However, last year in March due to many issues of privacy Apple decided to delete the zoom software from the app store. The reason being that every call has a digitally generated meeting code, an ID number containing 9 to 11 digits, which can easily be broken by a hacker [16].

\section{Methodology}

For an overall methodology, in this research we proposed a framework to develop a webinar and studied the features of the webinar suitable for adult training of entrepreneurs from the northern Thai province to be engaged in long term courses. In order to develop a suitable webinar platform to address our research objective, we employed the framework based on the proposed method of [17], and the software engineering approaches adapted from the waterfall model [18][19], and we proposed a sequential framework approach consisting of three stages shown in Figure 1.

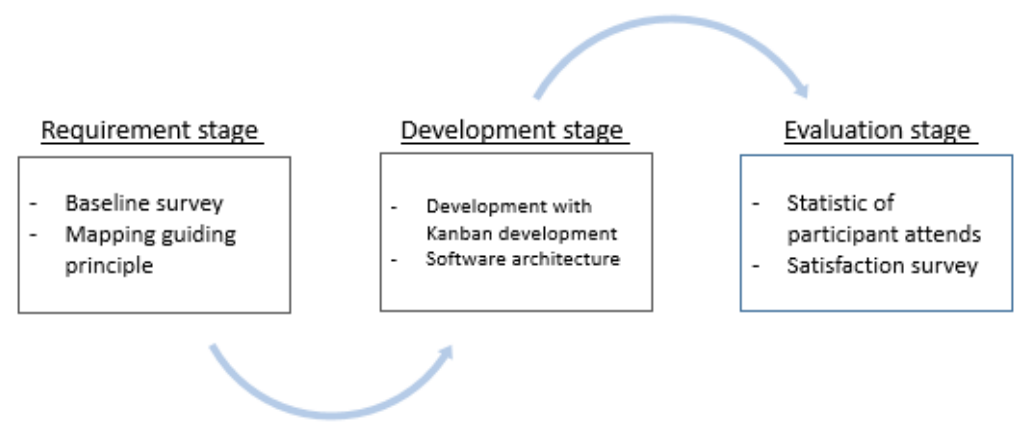

Fig. 1. The proposed general framework for webinar. 


\section{$4 \quad$ Requirement stage}

In the requirement stages, we planned to collect data from participants' experiences of learning with webinar or web conference. Thus, we used both quantitative and qualitative method including an online survey questionnaire and informal interviews with training participants. In order to avoid the impact and reflexivity of data collection, we followed the guidelines [20] for the basics of qualitative research techniques for data generation and analysis. Our aim was to understand the experiences, motivation, problems, attitude, interactions and another issue by participants. This stage consists of two processes as described below.

\subsection{Baseline survey of other functionalities}

A key aspect of the baseline survey is to understand the overall use and perceptions of adult training via webinars within the program of training for entrepreneurs of SMEs. Accordingly, we used both qualitative and quantitative methods to investigate the issue of participation. For a quantitative approach, we adapted the online survey [21] suitable for employees and entrepreneurs for formal and informal meetings and training. The questionnaire consisted of 12 questions with two open-ended questions asking participants for their experience, how audiences should be engaged and what feature should be implemented into the webinar to keep the training successful. There are totally 411 employees and entrepreneurs from the northern province of Thailand responding to the survey, the statistics are shown in Table 1.

Table 1. The statistics of questionnaire responses from Northern Thailand.

\begin{tabular}{|l|c|c|c|c|c|c|}
\hline \multicolumn{1}{|c|}{ Province } & $\begin{array}{c}\text { Online } \\
\text { form }\end{array}$ & Email & $\begin{array}{c}\text { Telephone } \\
\text { interview }\end{array}$ & employees & entrepreneurs & $\begin{array}{c}\text { Total par- } \\
\text { ticipants }\end{array}$ \\
\hline Phrae & 40 & 10 & 7 & $70.17 \%(40)$ & $29.82 \%(17)$ & 57 \\
\hline Lamphun & 50 & 6 & 2 & $86.20 \%(50)$ & $13.79 \%(8)$ & 58 \\
\hline Chiang Rai & 97 & 12 & 10 & $71.42 \%(85)$ & $28.57 \%(34)$ & 119 \\
\hline Lampang & 70 & 8 & 20 & $91.83 \%(90)$ & $8.16 \%(8)$ & 98 \\
\hline Chiang Mai & 60 & 14 & 5 & $77.21 \%(61)$ & $22.78 \%(18)$ & 79 \\
\hline & 317 & 50 & 44 & $79.31 \%(326)$ & $20.68 \%(85)$ & 411 \\
\hline
\end{tabular}

The brief report of questionnaire showing the top three ranks for each section

- Respondents ranked the top three most used software for webinar as Zoom

- $(91.51 \%)$, webex meeting (7.23\%), Google Hangouts (1.26\%).

- The most frequent activity in webinar for SMEs are: administrative work $(52.25 \%)$, meetings (35.21\%), training and teaching (12.05\%).

- The webinar features used during meetings are: screen sharing (63\%), video recording $(32.12 \%)$, chat $(4.21 \%)$.

- The participants described webinars as "Feasible and convenient" (51\%), "convenient" (25.25\%),"Feasible" (22\%). 
In terms of a qualitative survey, we interviewed participants for a deeper insight of good and bad interaction experiences during the webinar. The objective of interviews was to find the suitable embedded features of webinar facilitating engagement among webinar participants. We divided the participants into three groups for the interviews: audience, instructor and organizer of training. We summarized (see table 2) the other list of features and other issues as follows.

Table 2. List of features of the baseline survey from the participants.

\begin{tabular}{|l|l|l|}
\hline Participants & Features of training requirements & Note from participants \\
\hline Audience & $\begin{array}{l}\text { Web base of webinar standalone for both } \\
\text { desktop and mobile } \\
\text { notification system before meeting such as } \\
\text { email, sms } \\
\text { Easy way to access webinar }\end{array}$ & $\begin{array}{l}\text { Improve knowledge which has an ex- } \\
\text { isting base of knowledge and life ex- } \\
\text { perience }\end{array}$ \\
\hline Instructor & $\begin{array}{l}\text { Monitor of audience during program train- } \\
\text { ing } \\
\text { Raise Hand } \\
\text { Breakout rooms } \\
\text { Keyboard control } \\
\text { Whiteboard }\end{array}$ & $\begin{array}{l}\text { Engage audience during using webi- } \\
\text { nars }\end{array}$ \\
\hline $\begin{array}{l}\text { Organizer of } \\
\text { training }\end{array}$ & $\begin{array}{l}\text { Schedule plan management system } \\
\text { Software engi- } \\
\text { neering }\end{array}$ & $\begin{array}{l}\text { Webinar Management system for par- } \\
\text { ticipants to engage for the whole } \\
\text { course of training }\end{array}$ \\
\hline
\end{tabular}

However, the table excludes the list of features dependent on internet infrastructure and audio technology of users such as "do not hear the voice clearly", "internet connection", "disconnect many times" and find somewhat the important feature to motivate and engage the audience and attendees during open questions and keep them engaged until the end of meeting.

\subsection{Mapping the guiding principle with a subject matter expert}

The objective of the development design of webinars was to keep the attendees engaged during training time. Based on previous studies, the engagement time for learning in MOOC is not more than approximately five to six minutes [22]. However, webinar allows for interactive seminars through synchronous communication between the audience and instructor. The important advantages of webinars are the suitable personal meetings, the ease of access, immediate feedback, reusable learning by record, and remote presence for administration work without travel costs required [23] [24]. In order to design effective webinars for SME trainings, we employed the concept of the Knowledge expert co-creation-based framework [25] which involves knowledge experts who participated in direct and indirect webinars applied to a field-based environment. The idea of the framework is to exchange the knowledge between the expert who is involved in the system. Educators, attendees in the sector of SMEs, instructors/trainers in the sector of SMEs, organizer and software engineers are involved to ensure that the webinar would be effective for the training of SMEs. We also employed the concept 
of promoting the learning cycle to support learners [21] to find the suitable feature requirement from the data gathering of previous surveys.

Table 3. Webinar based on the learning cycle of the 4Es instructional model.

\begin{tabular}{|c|c|c|}
\hline Learning cycle & $\begin{array}{l}\text { Requirement Functionalities in } \\
\text { Webinar }\end{array}$ & Organizer support Notes for SMEs \\
\hline Engagement & $\begin{array}{l}\text { - Video direct facetime } \\
\text { - Digital phone call } \\
\text { - Web base of webinar standalone for } \\
\text { both desktop and mobile } \\
\text { - notification system before meeting }\end{array}$ & $\begin{array}{l}\text { - Schedule plan for a live webinar or } \\
\text { to record the webcast } \\
\text { - poster or webinfo to engage learner } \\
\text { - Webinar invitation and learning ob- } \\
\text { jectives }\end{array}$ \\
\hline Exploration & $\begin{array}{l}\text { - Sharing resource file } \\
\text { - Screen sharing } \\
\text { - Provide links to course related resources }\end{array}$ & $\begin{array}{l}\text { - Self \& peer evaluation rubrics } \\
\text { - linking with another course module }\end{array}$ \\
\hline Explanation & $\begin{array}{l}\text { - File and resource sharing } \\
\text { - Whiteboard } \\
\text { - Video/audio record }\end{array}$ & $\begin{array}{l}\text { - Discussion forum } \\
\text { - Learning resources in direct web } \\
\text { - valuable resources from } \\
\text { social media } \\
\text { - Curriculum web resources }\end{array}$ \\
\hline Extension & $\begin{array}{l}\text { - notification system for next meeting } \\
\text { - File and resource sharing } \\
\text { - Schedule plan management }\end{array}$ & $\begin{array}{l}\text { - Webinar technology how to use \& } \\
\text { tutorials } \\
\text { - Working on group activities } \\
\text { - Provide learning resources repository } \\
\text { for file sharing }\end{array}$ \\
\hline
\end{tabular}

Based on table 3, we defined the requirement functionalities to design a webinar based on a learning cycle for effective learning from the 4Es instructional model [21]. The model framework included the learning cycle, engagement, exploration, extension and explanation [26]. We summarized each learning cycle below.

Engagement: This learning cycle focused on the engagement of the audience, and the improvement of motivation by linking the audience to the course on a personal level. The functionalities in Webinar provided a flexible way for the audience to keep connected to the system. The notification system increases audience engagement before the start of the course including interesting posters and details of the course enhancing the motivation of the audience to join the classroom.

Exploration: This learning cycle reinforces understanding, it applies practices and concepts of the process during the learning through the webinar and provide related concepts. The functionalities support the audience in better exploring the knowledge related to the course. Shared resource and screen sharing support the audience in obtaining more knowledge related to the course.

Explanation: The objective of this cycleis to make the realize how the prior knowledge and course objectives align with the findings from the Exploration. The functionalities of the tool provides the possibility of cooperation with other audiences or instructors for more explanation of the course during or after finishing the classroom activity. Whiteboard and recorder tools support the instructors and the audience in seeking explanations. 
Extension: The last cycle which it also the first phase of the next learning cycle, the extension phase provides understanding by combining or joining concepts with concepts that make more complex understandings. The functionalities support further generalizations of the knowledge and also the preparation for the next meeting

The main knowledge from our subject matter expert is the blueprint sent to the developer team and the organizer of the training to make sure the webinar technology is suitable for the audience and instructor of the SME sector.

\section{Development stage}

\subsection{Webinar development with Kanban software development projects}

In the following sections, to develop webinar, we consider the kanban [27] theory as a suitable software modeling to develop the project because it is based on the clear feature list of webinar and provides a clear representation of all activities of processes in the project. Basically, kanban is a software management model that separates each task by prioritizing according to importance in order to reduce the risk of incomplete development task and also helps for a flexibility towards other tasks in the project.

The core concept of the Kanban methodology is the visualization of the workflow to show the progress of the project to team members as shown in Figure 2. This section explains the steps of implementing the kanban methodology for webinar.

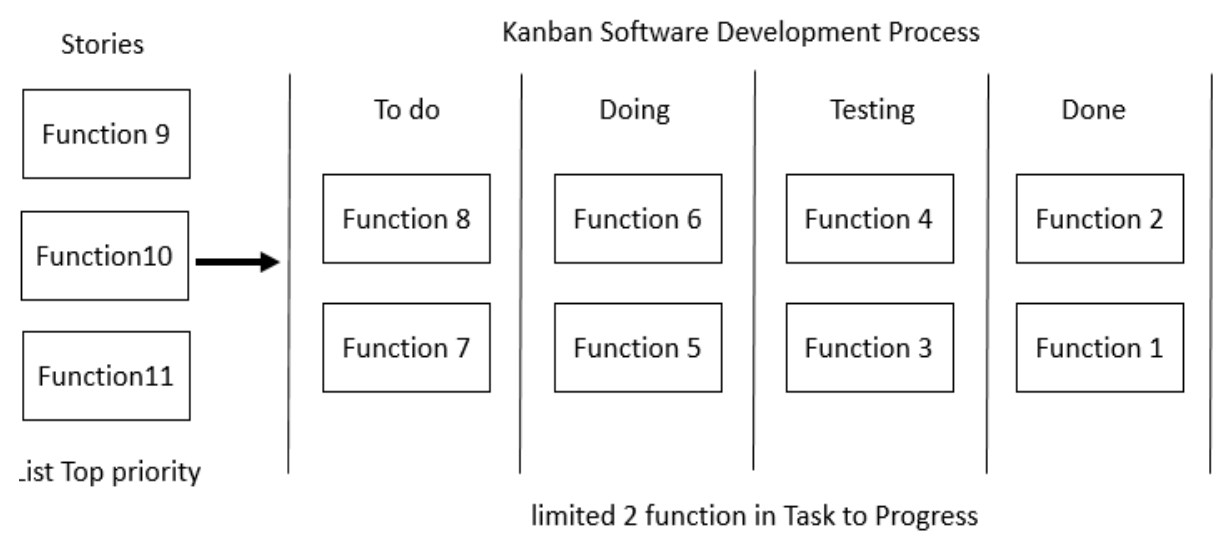

Fig. 2. Example of the Kanban methodology

\subsection{Software Architecture Webinar for SMEs}

The webinar for SMEs aims to customize the features of commercial webinars that are suitable for the training of SMEs in northern Thailand. To customize the webinar with the kanban methodology, the first step was designing a software architecture based on the requirements from the previous section. Actually, we separated the development 
into two parts: the proposed architecture for webinar consists of a Backend and Frontend system as shown in Figure 3.

The backend system aims to organize the corporate back-office of the webinar consisting of the Core video, the Notification system, the Webinar management system, and the Administration system.

- Core video API with OpenTok: it is used to control the whole video session. We considered using OpenTok API (https://tokbox.com/) which is the core of Video API

- Notification system: This system used to manage the SMS and Emails to notify users and inform them before the training meeting section begins.

- Webinar management system: The core system of webinar management to connect other systems. We decided to develop it based on PHP 7.0 and Mysq1 5.7.

- Administration system: The system designed for the organizers of the training to manage the schedule plan and insert the information of the audience and instructor to the class section.

- Frontend system is directly accessed and interacted with the webinar consisting of the Portal system, and the web-based webinar platform for mobile and desktop.

- Portal system: the module for management members to access the webinar system for all participants.

- Web based webinar platform for mobile and desktop: the webinar interface designed for mobile users. We used bootstrap 5.0 as the framework for frontend.

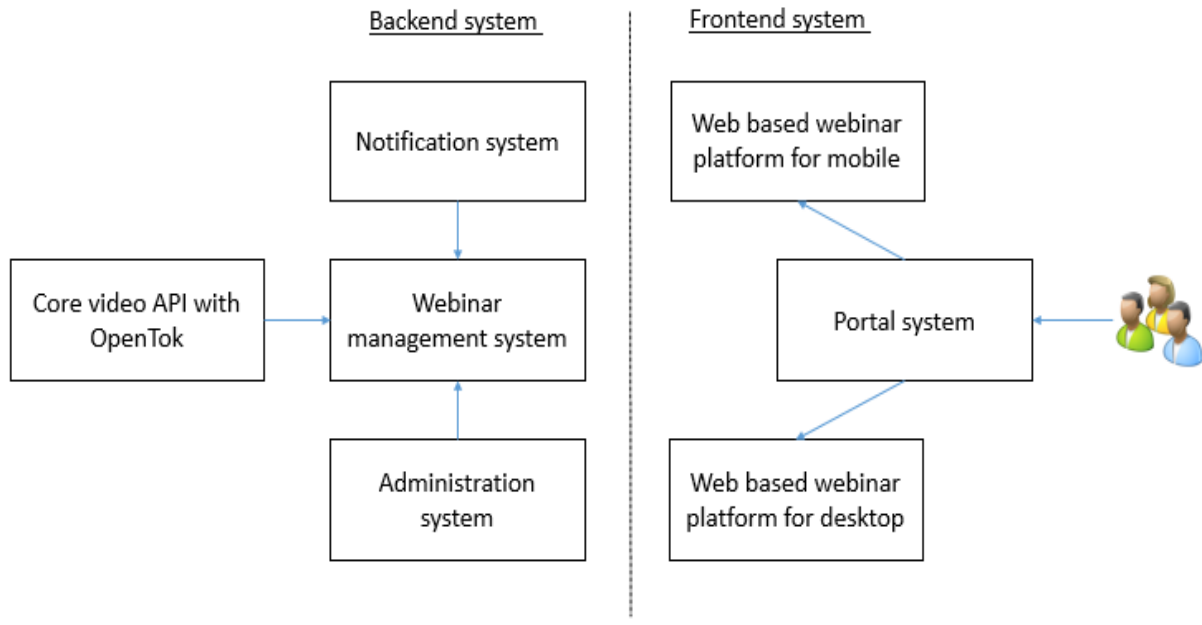

Fig. 3. Software Architecture Webinar for SMEs.

\subsection{Visualizing the tasks on the card wall}

The concept of task visualization with "card wall" is used to summarize the whole process and define clear goals for kanban software development projects. All tasks are assigned into cards or sticky notes and each card is put on the wall or kanban backlog 
based on the status in order to conclude the progress of the project. In our case, the status of tasks are "to do", "development", "testing", and "done". Once the task is complete for each status, it is moved to the next step until the task completes, then the next function in stories will be put on the wall. In order to effectively manage the project, the task visualization on the card wall could manage the queue of tasks and show the possible remaining tasks in the project. We used the application called Trello to manage our projects as shown in Figure 4.

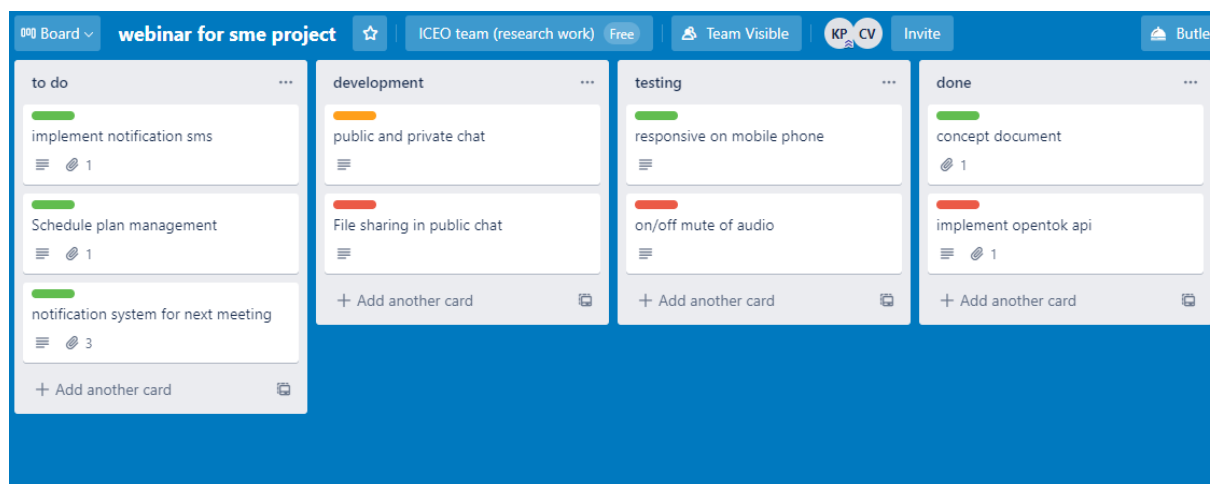

Fig. 4. Example of task visualization in Trello application.

\subsection{Color label to visually represent the task}

The card wall allows to visually represent the tasks, and also to reveal the progress of the team and the time left to complete the task. Another benefit of the Kanban methodology is that it also shows the bottlenecks of work and the gap between the tasks, so that the project managers can solve and estimate the possible timeline of the project management. We assigned colors to cards, where the color defined the urgency of the task: "green", "orange" and "red" was assigned to "normal","should do", and "urgent" respectively. The visual color labels are used to estimate the time and allocate budget for the cost constraints of the project to meet the deadline of the actual project as shown in Figure 5.

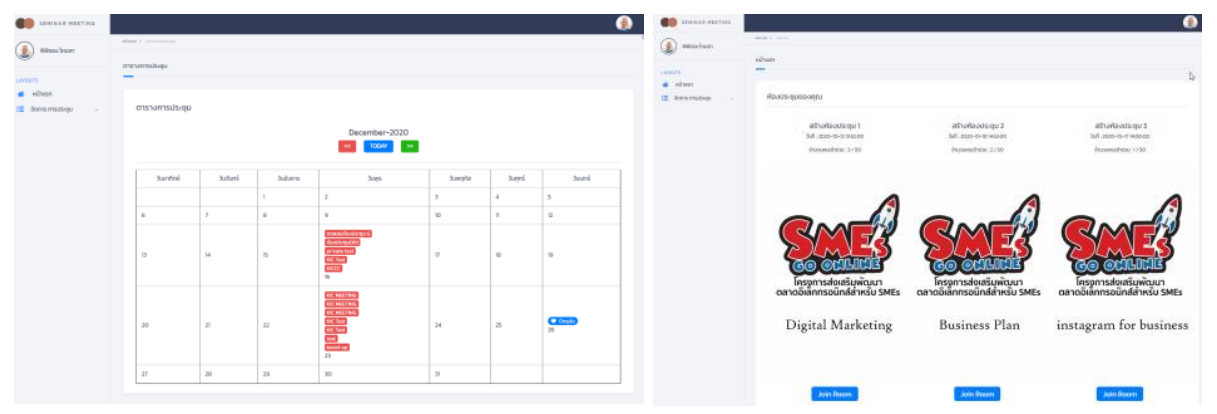

Fig. 5. Example of using schedule plan management to organize the program. 


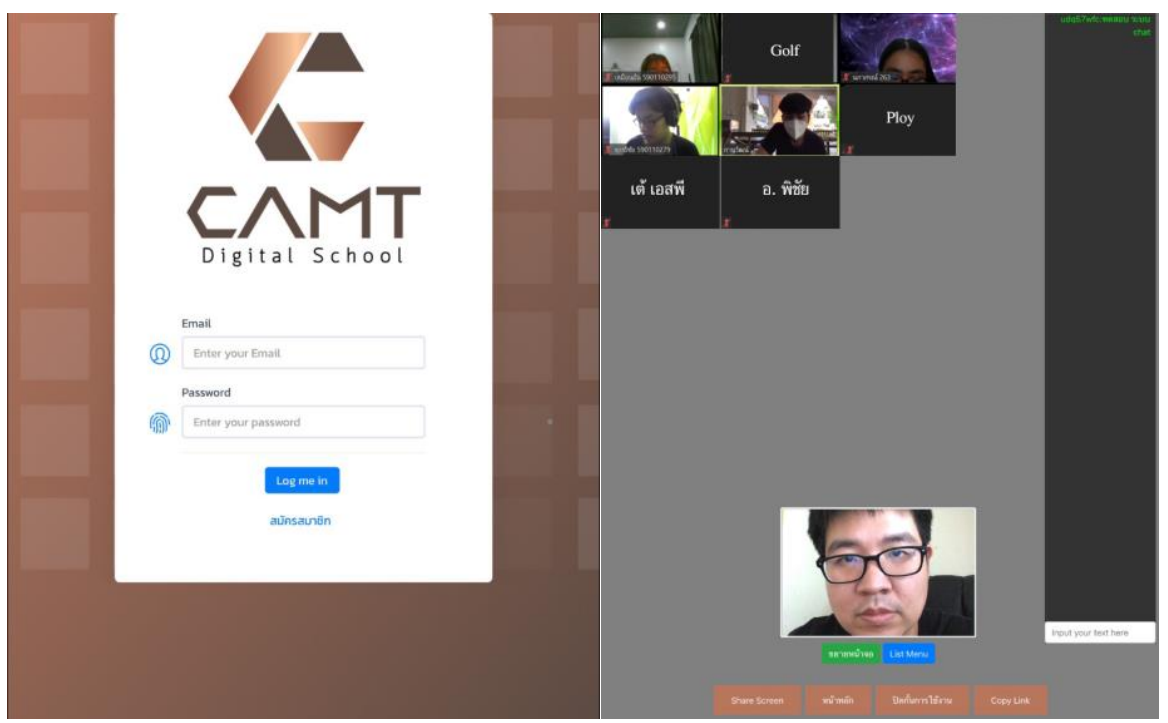

Fig. 6. Example of portal and interface during a webinar session

\section{Evaluation stage}

\subsection{Evaluation of learners' feelings towards the proposed approach}

The research presented had gathered data with the participation of 110 employees and entrepreneurs from the northern Thai province who joined the project of "Increase the potential of entrepreneurs with Digital Marketing" supported by the Office of Small and Medium Enterprise Promotion (www.sme.go.th) and Chiang Mai University funded by the Thai government. The objective of this curriculum is to train entrepreneurs enhancing their skills of digital marketing in small and medium enterprises in the northern provinces of Thailand.

To complete this study, we separated participants into two groups with fifty-five people in each group (see Table 4) asking for feedback and evaluate through a satisfaction survey to compare and evaluate our customized webinar platform. The objective was to evaluate the usability and satisfaction of our platform compared to other commercial webinar platforms suitable for our participants.

Table 4. ummary of the evaluation of two groups

\begin{tabular}{|c|c|c|c|c|c|}
\hline $\begin{array}{c}\text { Course } \\
\text { name }\end{array}$ & participants & Total time and session & Method & Webinar usage \\
\hline 1 & $\begin{array}{c}\text { Social } \\
\text { commerce }\end{array}$ & 55 & $\begin{array}{c}10 \text { hour / lecture } \\
10 \text { hour / workshop }\end{array}$ & $\begin{array}{c}5 \text { times / group based webinar } \\
5 \text { times / face to face webinar }\end{array}$ & Our webinar \\
\hline 2 & $\begin{array}{c}\text { Social } \\
\text { commerce }\end{array}$ & 55 & $\begin{array}{c}10 \text { hour / lecture } \\
10 \text { hour / workshop }\end{array}$ & $\begin{array}{c}5 \text { times / group based webinar } \\
5 \text { times / face to face webinar }\end{array}$ & zoom \\
\hline
\end{tabular}


Group 1 and 2 took the course "social commerce". The specific objective of the course was to make learners understand what system is fundamental for retailers to adopt seamless and efficient digital payment solutions to complete a customer-centric buying experience on popular social media platforms and include search engines, define how to choose the right keyword themes, and how to create and implement SEO for small and medium enterprises. Both groups took 10 hours of distance lectures based of fundamentals and theory through a webinar platform and 10 hours of face-to-face lectures via webinar and they also received advice through a one-on-one workshop specified for each product of their own company. Note that both groups were taught by the same lecturer but on a different webinar platform.

From the statistics of Figure 7 showing the number of participants attending each course, we found that Group 1 (our webinar platform) has a higher average (38.6 and 31.33 persons) of participant attendance than Group 2 (Zoom application) with 8 persons per time session. Accordingly, the participants reported that our webinar platform can more easily accessed than the zoom application because the notification system automatically sends sms and email directly to participants which can be clicked more comfortably to join the course.

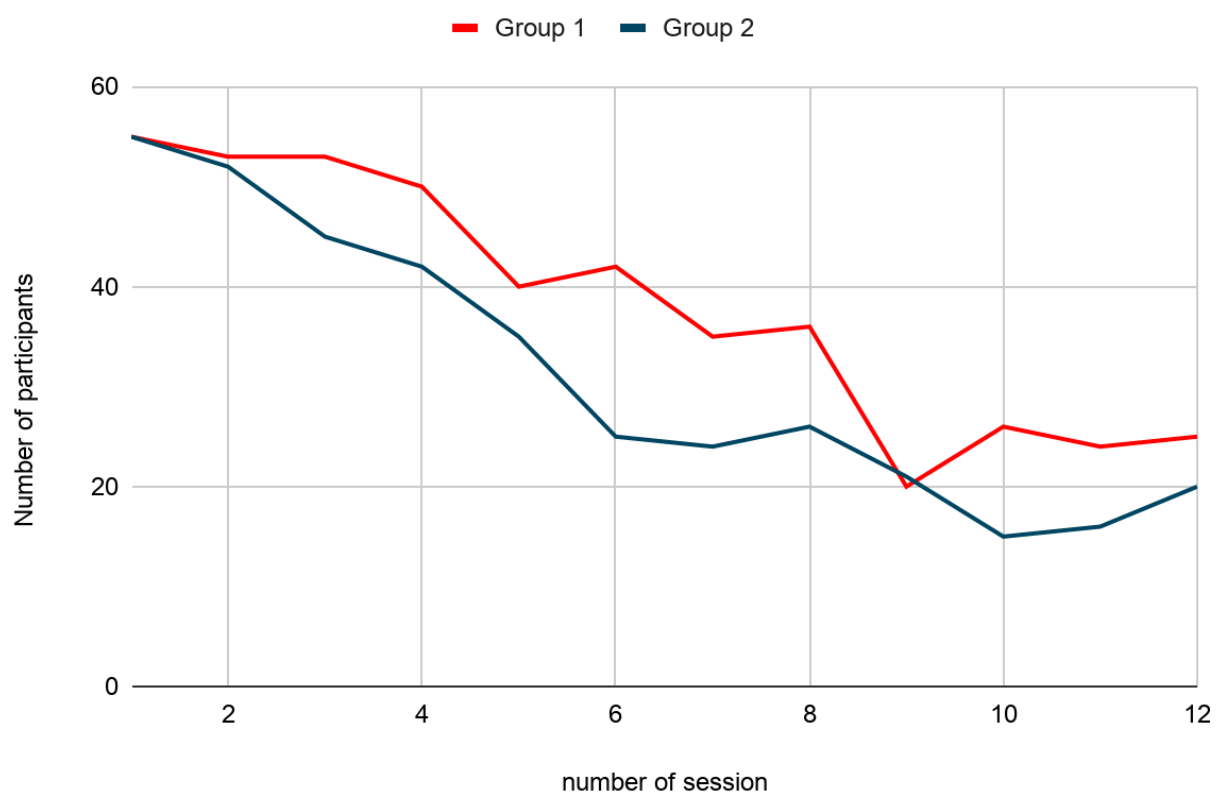

Fig. 7. Number of participants and webinar sessions

To summarize this study, we asked all participants of both groups to take a satisfaction survey, to measure the engagement and quality of the technology usage for the webinar applied for the training system. We surveyed the participants by Google form after finishing the training course. The questionnaire consists of 8 questions, each question has 5 options: very satisfied, satisfied, neither satisfied / unsatisfied, Dissatisfied and very dissatisfied. The questions focused on the quality of the technology usage for 
webinar (e.g., easy to access, system stability, user interface, quality of interactive) the learning experience (e.g., clearly informs the learning object, features used for learning, motivation) and the overall participant satisfaction.

The results show a very high ratio of satisfaction towards the quality of the training, 74.54\% for group1, and 78.18\% for group 2. Question numbers 1, 2, 3 and 4 compared the quality of our webinar platform and that of zoom. With regard to webinar platform used during training (see table 5, question 1,2,3,4), participants found that for group 1 , the webinar crashed sometimes $(21.81 \%$ and $74.54 \%)$ and they also highlighted confusing user interface and poor usability $(21.81 \%$ and $43.63 \%)$ compared to the zoom software. However, our platform was better in terms of easy access and friendly use (76.36\% and 58.18\%) due to the notification system via SMS and email (only one click to access) compared to the zoom software which is quite difficult and confusing when providing ID meeting for the group of participants.

In terms of webinar support technology features for teaching, the information of the learning objectives and pre-section (question 5,6) compared to the zoom application was very well received $(81.81 \%$ and $69.09 \%, 65.45 \%$ and $61.81 \%)$ because our webinar was customized to inform participants about the description and learning objective before joining the session, unlike the zoom application where it was difficult to describe the information for long term training. Nevertheless, with regards to the feature and general satisfaction the two groups were not quite different. The participants pointed out that the management for long term training and the quality of instructors were more essential than technology to support the training.

Table 5. Result of satisfaction survey

\begin{tabular}{|c|c|c|c|c|c|}
\hline & $\begin{array}{c}\text { Very } \\
\text { Satisfied }\end{array}$ & Satisfied & $\begin{array}{c}\text { Neither satisfied / } \\
\text { unsatisfied }\end{array}$ & Dissatisfied & \begin{tabular}{|c|} 
Very \\
dissatisfied
\end{tabular} \\
\hline $\begin{array}{l}\text { 1. The webinar was easy to access } \\
\text { from your own device }\end{array}$ & $\begin{array}{l}42(76.36 \%) \\
32(58.18 \%)\end{array}$ & $\begin{array}{l}13(23.63 \%) \\
15(27.27 \%)\end{array}$ & $\begin{array}{c}0(0.00 \%) \\
8(14.54 \%)\end{array}$ & $\begin{array}{l}0(0.00 \%) \\
0(0.00 \%)\end{array}$ & $\begin{array}{l}0(0.00 \%) \\
0(0.00 \%)\end{array}$ \\
\hline $\begin{array}{l}\text { 2. The system stability was quite } \\
\text { good (no crash or disconnection) }\end{array}$ & $\begin{array}{l}21(38.18 \%) \\
41(74.54 \%)\end{array}$ & $\begin{array}{c}20(36.36 \%) \\
4(7.27 \%)\end{array}$ & $\begin{array}{l}4(7.27 \%) \\
0(0.00 \%)\end{array}$ & $\begin{array}{l}0(0.00 \%) \\
0(0.00 \%)\end{array}$ & $\begin{array}{l}0(0.00 \%) \\
0(0.00 \%)\end{array}$ \\
\hline $\begin{array}{l}\text { 3. User interface and usability of } \\
\text { the webinar was quite good }\end{array}$ & $\begin{array}{l}12(21.81 \%) \\
24(43.63 \%)\end{array}$ & $\begin{array}{l}20(36.36 \%) \\
21(38.18 \%)\end{array}$ & $\begin{array}{l}15(27.27 \%) \\
9(16.36 \%)\end{array}$ & $\begin{array}{l}5(9.09 \%) \\
1(1.81 \%)\end{array}$ & $\begin{array}{l}3(5.45 \%) \\
0(0.00 \%)\end{array}$ \\
\hline $\begin{array}{l}\text { 4. During distance training, the } \\
\text { interaction between the instructor } \\
\text { and audience was quite good }\end{array}$ & $\begin{array}{l}21(38.18 \%) \\
30(54.54 \%)\end{array}$ & $\begin{array}{l}15(27.27 \%) \\
11(20.00 \%)\end{array}$ & $\begin{array}{l}15(27.27 \%) \\
13(23.63 \%)\end{array}$ & $\begin{array}{l}4(7.27 \%) \\
1(1.81 \%)\end{array}$ & $\begin{array}{l}0(0.00 \%) \\
0(0.00 \%)\end{array}$ \\
\hline $\begin{array}{l}\text { 5. The learning objective for each } \\
\text { session for this teaching was } \\
\text { clearly presented }\end{array}$ & $\begin{array}{l}45(81.81 \%) \\
38(69.09 \%)\end{array}$ & $\begin{array}{c}8(14.54 \%) \\
10(18.81 \%)\end{array}$ & $\begin{array}{c}2(3.63 \%) \\
7(12.72 \%)\end{array}$ & $\begin{array}{l}0(0.00 \%) \\
0(0.00 \%)\end{array}$ & $\begin{array}{l}0(0.00 \%) \\
0(0.00 \%)\end{array}$ \\
\hline $\begin{array}{l}\text { 6. The precondition for each } \\
\text { teaching session } \\
\text { was clearly presented }\end{array}$ & $\begin{array}{l}36(65.45 \%) \\
34(61.81 \%)\end{array}$ & $\begin{array}{l}15(27.27 \%) \\
12(21.81 \%)\end{array}$ & $\begin{array}{c}4(7.27 \%) \\
9(16.36 \%)\end{array}$ & $\begin{array}{l}0(0.00 \%) \\
0(0.00 \%)\end{array}$ & $\begin{array}{l}0(0.00 \%) \\
0(0.00 \%)\end{array}$ \\
\hline $\begin{array}{l}\text { 7. The features in the webinar } \\
\text { were presented in a stimulating } \\
\text { and motivating manner }\end{array}$ & $\begin{array}{l}34(61.81 \%) \\
35(63.63 \%)\end{array}$ & $\begin{array}{l}10(18.81 \%) \\
18(32.72 \%)\end{array}$ & $\begin{array}{c}11(20.00 \%) \\
2(3.63 \%)\end{array}$ & $\begin{array}{l}0(0.00 \%) \\
0(0.00 \%)\end{array}$ & $\begin{array}{l}0(0.00 \%) \\
0(0.00 \%)\end{array}$ \\
\hline $\begin{array}{l}\text { 8. You were generally satisfied } \\
\text { with the quality of the training } \\
\text { provided }\end{array}$ & $\begin{array}{l}41(74.54 \%) \\
43(78.18 \%)\end{array}$ & $\begin{array}{l}12(21.81 \%) \\
10(18.81 \%)\end{array}$ & $\begin{array}{l}2(3.63 \%) \\
2(3.63 \%)\end{array}$ & $\begin{array}{l}0(0.00 \%) \\
0(0.00 \%)\end{array}$ & $\begin{array}{l}0(0.00 \%) \\
0(0.00 \%)\end{array}$ \\
\hline
\end{tabular}


The results show a very high ratio of satisfaction towards the quality of the training, $74.54 \%$ for group1, and $78.18 \%$ for group 2. Question numbers 1, 2, 3 and 4 compared the quality of our webinar platform and that of zoom. With regard to webinar platform used during training (see table 5, question 1,2,3,4), participants found that for group 1 , the webinar crashed sometimes $(21.81 \%$ and $74.54 \%)$ and they also highlighted confusing user interface and poor usability $(21.81 \%$ and $43.63 \%)$ compared to the zoom software. However, our platform was better in terms of easy access and friendly use (76.36\% and $58.18 \%$ ) due to the notification system via SMS and email (only one click to access) compared to the zoom software which is quite difficult and confusing when providing ID meeting for the group of participants.

In terms of webinar support technology features for teaching, the information of the learning objectives and pre-section (question 5,6) compared to the zoom application was very well received $(81.81 \%$ and $69.09 \%, 65.45 \%$ and $61.81 \%)$ because our webinar was customized to inform participants about the description and learning objective before joining the session, unlike the zoom application where it was difficult to describe the information for long term training. Nevertheless, with regards to the feature and general satisfaction the two groups were not quite different. The participants pointed out that the management for long term training and the quality of instructors were more essential than technology to support the training.

\section{Conclusions}

At the beginning of 2020, the COVID-19 pandemic in Thailand led the government deciding to order a lockdown in response to the COVID-19 pandemic. Schools and education institutions quickly transformed their educational systems replacing face-toface lectures with distance learning. In particular, many commercial webinar platforms have been used to ensure the smooth running of the training process but they still lack the functionalities to manage the participants in long term courses.

In our research, we proposed the development of customized webinar platforms for the training of entrepreneurs of SMEs from Northern Thailand. We collected a baseline survey to select the features of the webinar as best practices to engage participants in the webinar to attend the course. The Kanban methodology was used for the development process tracking it feature by feature.

To evaluate the platform, we compared the zoom software with our approach both qualitatively and quantitatively. After all, the bottom line feature of the technology integration is to encourage participants to become active in their learning during long term courses. The results of the various knowledge tests show that the feature of notification systems and providing easy access to the webinar were important to engage participants and manage long term courses. However, customizing the webinar may cost a lot and may be time consuming. More importantly, customizing the webinar in adult training can be limited by the lack of motivation of learners.

This paper explores the opportunities of the adaptation of the webinar technology such as the interaction between learners and instructors, collaboration with peers and an enhanced engagement during the learning process. The examples of the studies on 
the webinar functionalities have shown an enhanced learner engagement in the long term courses. Further follow up studies should be conducted to implement machine learning to gather the webinars' usage data of the learner to understand each learning style of each learner to be adapted, based on the functionalities of learner behavior that increase the effectiveness of using webinars in adult training.

\section{Acknowledgements}

A project supported by The Office of SMEs Promotion (OSMEP) and Chiang Mai University.

\section{$9 \quad$ References}

[1] Abernathy, W. J., \& Clark, K. B. (1985). Innovation: Mapping the winds of creative destruction. Research policy, 14(1), 3-22. https://doi.org/10.1016/0048-7333(85)90021-6

[2] Henriksen, D., Creely, E., \& Henderson, M. (2020). Folk Pedagogies for Teacher Transitions: Approaches to Synchronous Online Learning in the Wake of COVID-19. Journal of Technology and Teacher Education, 28(2), 201-209.

[3] Bell, B. S., Tannenbaum, S. I., Ford, J. K., Noe, R. A., \& Kraiger, K. (2017). 100 years of training and development research: What we know and where we should go. Journal of Applied Psychology, 102(3), 305. https://doi.org/10.1037/ap10000142

[4] Goe, R., Ipsen, C., \& Bliss, S. (2018). Pilot testing a digital career literacy training for vocational rehabilitation professionals. Rehabilitation Counseling Bulletin, 61(4), 236-243. https://doi.org/10.1177/0034355217724341

[5] Testers, L., Gegenfurtner, A., \& Brand-Gruwel, S. (2015). Motivation to transfer learning to multiple contexts. The school library rocks: living it, learning it, loving it, 473-487. https://doi.org/10.29173/ias17472

[6] Testers, L. B. J. C. T., Gegenfurtner, A., van Geel, R., \& Brand-Gruwel, S. (2019). From monocontextual to multicontextual transfer: organizational determinants of the intention to transfer generic information literacy competences to multiple contexts. Frontline Learning Research, 7(1), 23-42. https://doi.org/10.14786/flr.v7i1.359

[7] Cornelius, S. (2014). Facilitating in a demanding environment: Experiences of teaching in virtual classrooms using web conferencing. British Journal of Educational Technology, 45(2), 260-271. https://doi.org/10.1111/bjet.12016

[8] Wang, Q., Huang, C., \& Quek, C. L. (2018). Students' perspectives on the design and implementation of a blended synchronous learning environment. Australasian Journal of Educational Technology, 34(1). https://doi.org/10.14742/ajet.3404

[9] Wang, S. K., \& Hsu, H. Y. (2008). Use of the webinar tool (Elluminate) to support training: The effects of webinar-learning implementation from student-trainers' perspective. Journal of interactive online learning, 7(3), 175-194.

[10] Basilaia, G., \& Kvavadze, D. (2020). Transition to Online Education in Schools during a SARS-CoV-2 Coronavirus Transition to Online Education in Schools during a SARS-CoV2 Coronavirus (COVID-19) Pandemic in Georgia. Pedagogical Research, 5(4). https://doi.org/10.29333/pr/7937

[11] Auer, M., \& Tsiatsos, T. (2018). The challenges of the digital transformation in education. ICL, Advances in Intelligent Systems and Computing, 916. 
[12] Kurbakova, S., Volkova, Z., \& Kurbakov, A. (2020, July). Virtual Learning and Educational Environment: New Opportunities and Challenges under the COVID-19 Pandemic. In 2020 The 4th International Conference on Education and Multimedia Technology (pp. 167-171). https://doi.org/10.1145/3416797.3416838

[13] Hubbard, M., \& Bailey, M. J. (2018). User Adoption in Teams. In Mastering Microsoft Teams (pp. 75-87). Apress, Berkeley, CA. https://doi.org/10.1007/978-1-4842-3670-3_5

[14] Martin, L., \& Tapp, D. (2019). Teaching with Teams: An introduction to teaching an undergraduate law module using Microsoft Teams. Innovative Practice in Higher Education, 3(3).

[15] LI, H. Y., \& GUO, M. R. (2017). Application of Zoom in Multisensory Teaching from the Perspective of Multisensory Integration. DEStech Transactions on Environment, Energy and Earth Sciences, (eesd). https://doi.org/10.12783/dteees/eesd2017/12005

[16] Aiken, A. (2020). Zooming in on privacy concerns: Video app Zoom is surging in popularity. In our rush to stay connected, we need to make security checks and not reveal more than we think. Index on Censorship, 49(2), 24-27. https://doi.org/10.1177/0306422020935792

[17] Cechetti, N. P., Bellei, E. A., Biduski, D., Rodriguez, J. P. M., Roman, M. K., \& De Marchi, A. C. B. (2019). Developing and implementing a gamification method to improve user engagement: A case study with an $\mathrm{m}$-Health application for hypertension monitoring. Telematics and Informatics, 41, 126-138. https://doi.org/10.1016/j.tele.2019.04.007

[18] Kramer, M. (2018). Best practices in systems development lifecycle: An analyses based on the waterfall model. Review of Business \& Finance Studies, 9(1), 77-84.

[19] Boehm, B. W. (1988). A spiral model of software development and enhancement. Computer, 2l(5), 61-72.

[20] Strauss, A., \& Corbin, J. (1998). Basics of qualitative research techniques. Thousand Oaks, CA: Sage publications.

[21] Lieser, P., Taf, S. D., \& Murphy-Hagan, A. (2018). The Webinar Integration Tool: A Framework for Promoting Active Learning in Blended Environments. Journal of Interactive Media in Education, 2018(1). https://doi.org/10.5334/jime.453

[22] Guo, P. J., Kim, J., \& Rubin, R. (2014). How video production affects student engagement: An empirical study of MOOC videos. In Proceedings of the first ACM conference on Learning@ scaleconference (pp. 41-50). https://doi.org/10.1145/2556325.2566239

[23] Guanci G. 2010. Best practices for webinars. Creat Nurs. 16(3):119-121.Hutten-Czapski P. 2014. Why webinar CME and why not. Can J Rural Med. 19(3):87. https://doi.org/ 10.1891/1078-4535.16.3.119

[24] Lieser P, Taff S, Murphy-Hagan A. 2018. The Webinar Integration Tool:a framework for promoting active learning in blended environments. JIME. 2018(1):7. https://doi.org/ $10.5334 /$ jime. 453

[25] Wegner, C., Weber, P., \& Ohlberger, S. (2014). Korthagen's ALACT Model: Application and Modification in the Science Project" Kolumbus-Kids". Themes in Science and Technology Education, 7(1), 19-34.

[26] Jenkins, H. (2009). Confronting the challenges of participatory culture: Media education for the 21 st century (p. 145). The MIT Press.

[27] Anderson, D. J. (2010). Kanban: successful evolutionary change for your technology business. Blue Hole Press. 


\section{Authors}

Dr. Pakinee Ariya is a lecturer in the college of art media and technology, Chiang Mai University, Thailand. She also works on Adult learning, technology management system and knowledge management.

Dr. Kannikar Intawong is a lecturer in faculty of public health. Chiang Mai University, Thailand. She also works on health information, health literacy, data science and technology management system.

Dr. Kitti Puriat is a lecturer in the department of Library and Information Science Faculty of humanities, Chiang Mai University, Thailand. He also works on information studies, knowledge management, gamification and machine learning.

Article submitted 2021-02-06. Resubmitted 2021-06-02. Final acceptance 2021-06-02. Final version published as submitted by the authors. 